\title{
Application research progress of hot isostatic pressing technology in nickel-based single crystal superalloy
}

\author{
Jun Wang ${ }^{*}$, Zhaojun Jiang, \\ Wuxi Institute of Technology, Wuxi, 214121, R.P. China
}

\begin{abstract}
Since the introduction of hot isostatic pressing (HIP) technology, it has been widely used in powder metallurgy forming and improving the densification of castings. With the increasing demand for the performance of nickel-based single crystal superalloy, more and more scholars started research on the application of hot isostatic pressing in nickel-based single crystal superalloy. This article summarizes the current research progress in the application of hot isostatic pressing to the high temperature of nickel-based single crystals, explains the elimination effect of hot isostatic pressing on porosity and other pore defects in nickel-based single crystal superalloy, analyzes the pore healing mechanism, and the changes in mechanical properties such as tensile, endurance, and fatigue of the alloy after applying hot isostatic pressing are shown. Finally, the future development of China's hot isostatic pressing technology is prospected.
\end{abstract}

\section{Introduction}

Nickel-based single crystal superalloy has become one of the most important materials for electric energy gas turbines due to their excellent fatigue and creep resistance at high temperatures and excellent resistance to oxidation and corrosion ${ }^{[1-3]}$. Compared with other cast superalloy, single crystal superalloy produced by investment casting have little porosity tendency ${ }^{[4]}$, but they still inevitably have defects such as porosity and segregation. Because of the dendrite growth mode during the solidification of alloy crystal, the dendrite region gradually becomes the final solidification region, and the metallic liquid cannot enter the dendrite region to shrink, resulting in the formation of micropores between dendrites. When the alloy is subject to solution heat treatment, defects such as solution micropores will also be formed due to the Kirkendall effect ${ }^{[5-6]}$, the diameter of these pores is about 10$30 \mu \mathrm{m}$, and the volume fraction is a few tenths of a percent ${ }^{[7]}$. During the alloy service life, void defects will become the source of cracks and cause the mechanical properties of the alloy to decline, which seriously reduces the service life of the material ${ }^{[8]}$.

Hot isostatic pressing technology is mainly used to heat metal or ceramic parts while applying the same pressure in all directions, so that the parts can be sintered and densified. The use of hot isostatic pressing technology can not only significantly eliminate defects in the alloy but also improve the internal microstructure and mechanical properties of the

\footnotetext{
*Corresponding author:boher@126.com
} 
alloy, and improve the reliability of the alloy ${ }^{[9]}$. At present, the main application fields of HIP technology are densification treatment of castings, powder metallurgy and bonding fixation of materials, accounting for $54 \%, 43 \%$ and $3 \%$ respectively. As the HIP technology has unique advantages in promoting the compactness of parts, eliminating void defects, reducing segregation and improving the mechanical properties of the alloy, it has gradually become the standard post-treatment process for turbine blades made of nickel base superalloy ${ }^{[10]}$. At present, the research of hot isostatic pressing (HIP) technology for the application of electrical energy superalloy in foreign countries has been relatively mature, and the HIP technology has been applied in the engineering of electrical energy superalloy. However, the research and application of HIP technology in the field of Single Crystal Superalloy for gas turbine electrical energy sources in China is not much ${ }^{[11]}$.

In order to eliminate the micro hole defects in gas turbine power materials, it is necessary to study the microstructure changes and pore healing of nickel base single crystal superalloy under different hot isostatic pressure parameters, understand the mechanism of pore healing, and avoid other defects in the alloy caused by hot isostatic pressure. This paper reviews the recent research and application of hot isostatic pressing technology in nickel-based single crystal superalloy for gas turbine power energy materials, analyzes hot research directions of hot isostatic pressing, and points out the development prospect of hot isostatic pressing technology in the field of nickel base single crystal superalloy.

\section{Effect of HIP on densification of nickel base single crystal superalloy}

\subsection{Effect of HIP parameters on porosity of nickel base single crystal superalloy}

The main process parameters involved in hot isostatic pressing include temperature, pressure and holding time. Different process parameters play different roles in promoting hole closure and improving the compactness of the workpiece. Taking temperature as an example, when the HIP temperature is higher than the solution temperature of $\gamma^{\prime}$ phase, the nickel base single crystal superalloy can be softened in the case of single phase, and the plasticity can be significantly improved, which is conducive to the closure of pores. However, when the temperature is close to the solidus temperature of the alloy, there is a risk of recrystallization and initial melting inside the material, which is strictly prohibited in engineering applications ${ }^{[12-13]}$. Therefore, in order to control the cost and ensure the quality of the parts, it is necessary to study the control and influence mechanism of different parameters of HIP treatment on the microstructure and properties of the alloy in detail, and select the optimal matching scheme of process parameters, so as to obtain the alloy material with significantly improved comprehensive performance and give full play to the advantages of HIP technology.

Cao ${ }^{[14]}$ studied the effect of different hot isostatic pressing temperature on the internal micro porosity of DD10 single crystal superalloy. Figure 1 shows the optical structure of DD10 single crystal superalloy as cast and treated by different hot isostatic pressing schemes. The results show that the micro porosity in the as cast alloy can be completely eliminated after being treated by isostatic pressing at $1290^{\circ} \mathrm{C}$ and $150 \mathrm{MPa}$. When the pressure is constant and the temperature is raised to $1300 \sim 1340^{\circ} \mathrm{C}$, the micro porosity in DD10 single crystal superalloy can also be completely closed. However, after $1340^{\circ} \mathrm{C}$, there is primary melting in the alloy. Therefore, the hot isostatic pressure temperature 
should not exceed $1340^{\circ} \mathrm{C}$ under $150 \mathrm{MPa}$ to avoid the initial melting of DD10 single crystal superalloy.

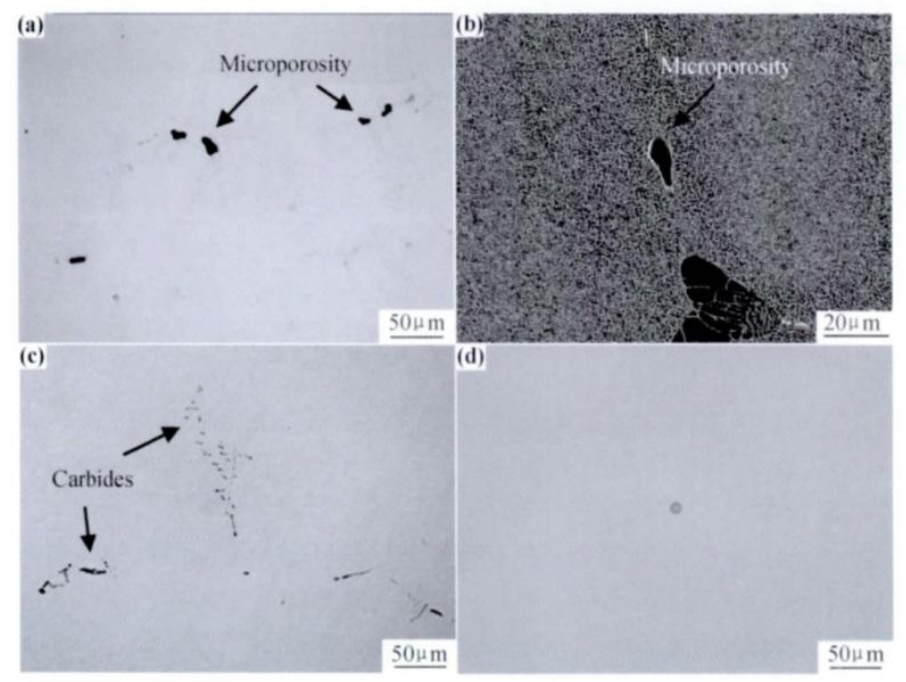

Fig.1. Distribution and morphology of micro porosity in single crystal superalloy DD10 at different conditions.

(a) As cast structure (b) as cast micro porosity SEM morphology

(c) $\mathrm{HIP}-1290^{\circ} \mathrm{C} / 150 \mathrm{MPa}$ optical structure (d) $\mathrm{HIP}-1340^{\circ} \mathrm{C} / 150 \mathrm{MPa}$ optical structure

Inmaculada Lopez-Galilea ${ }^{[15]}$ carried out a hot isostatic pressing process study on the single crystal superalloy ERBO-1 at different temperatures, pressure and holding time. The as cast sample (ERBO-1A) and the fully solution and aged sample (ERBO-1C) were selected for different hot isostatic pressing studies. The hot isostatic pressing process scheme shown in Table 1 was designed to study the effects of temperature and holding time on the pore closure of the two samples under the determined pressure conditions. Figure 2 shows the material porosity corresponding to different experimental results. It can be seen that the application of hot isostatic pressure has a significant effect on the reduction of material porosity, and the effect is more significant with increasing temperature. Regardless of the state of the sample, when the hot isostatic pressing temperature is higher than the $\gamma$ 'phase dissolution temperature (about $1260^{\circ} \mathrm{C}$ ), the sample pores are almost completely eliminated after the hot isostatic pressing regardless of the holding time of $3 \mathrm{~h}$ or $5 \mathrm{~h}$.

Table 1. Hot isostatic pressure scheme under determined pressure.

\begin{tabular}{|c|c|c|}
\hline $\begin{array}{c}\text { Temperatu } \\
\text { re }\left({ }^{\circ} \mathrm{C}\right)\end{array}$ & $\begin{array}{c}\text { holding time } \\
(\mathrm{h})\end{array}$ & $\begin{array}{c}\text { Pressure } \\
(\mathrm{MPa})\end{array}$ \\
\hline $\begin{array}{c}1100,1200, \\
1220,1320\end{array}$ & 3 & 200 \\
\hline $\begin{array}{c}1200,1220, \\
1300,1320\end{array}$ & 5 & 200 \\
\hline
\end{tabular}




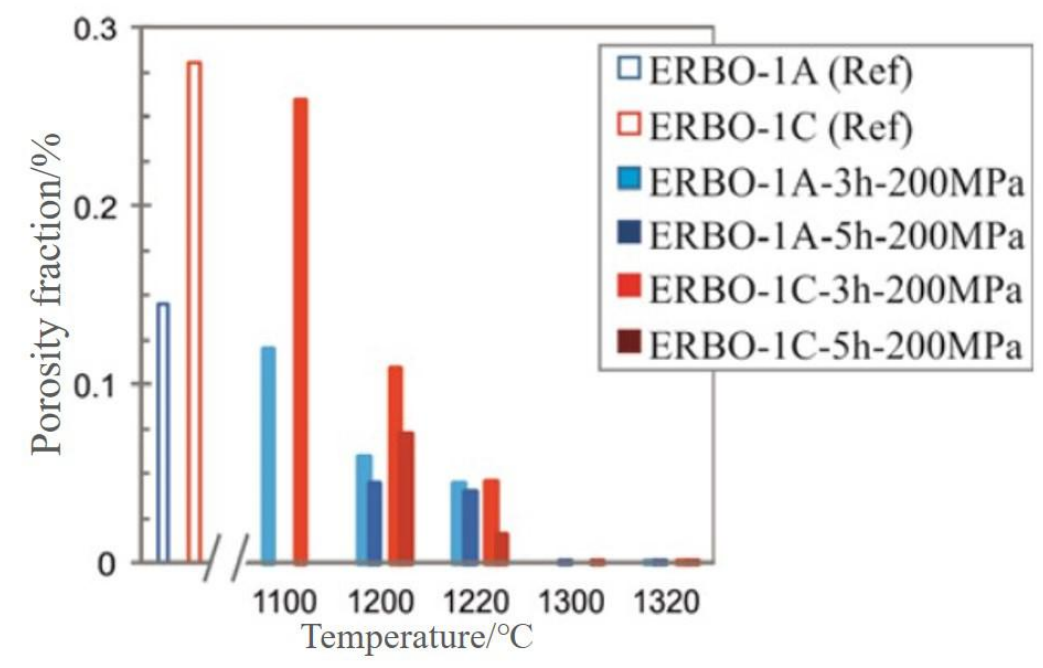

Fig. 2 Porosity of as-cast ERBO-1A and hardened ERBO-1C samples under different hot isostatic pressing schemes.

The hot isostatic pressing process scheme shown in Table 2 is designed to study the effect of temperature and pressure on the pore closure of as-cast samples under the condition of determining the holding time. Figure 3 shows the porosity of materials corresponding to different experimental results. It can be seen that under atmospheric pressure, the porosity of the material increases due to the solid solution micro porosity generated by the internal element diffusion under high temperature. When it is lower than the dissolution temperature of $\gamma$ 'phase, the porosity will indeed decrease with the increase of applied pressure, as shown in the blue column in Figure 3. However, when the temperature is higher than the dissolution temperature of $\gamma$ 'phase, the pores have been effectively closed at $100 \mathrm{MPa}$, as shown in the green column in Fig. 3, and further increase of pressure has no additional effect on the porosity.

Table 2. Hot isostatic pressure scheme for determination of holding time.

\begin{tabular}{|c|c|c|}
\hline Temperature $\left({ }^{\circ} \mathrm{C}\right)$ & holding time $(\mathrm{h})$ & pressure $(\mathrm{MPa})$ \\
\hline 1220 & 3 & $0.1,200,300$ \\
\hline $1200,1220,1300,1320$ & 3 & 100,200 \\
\hline
\end{tabular}




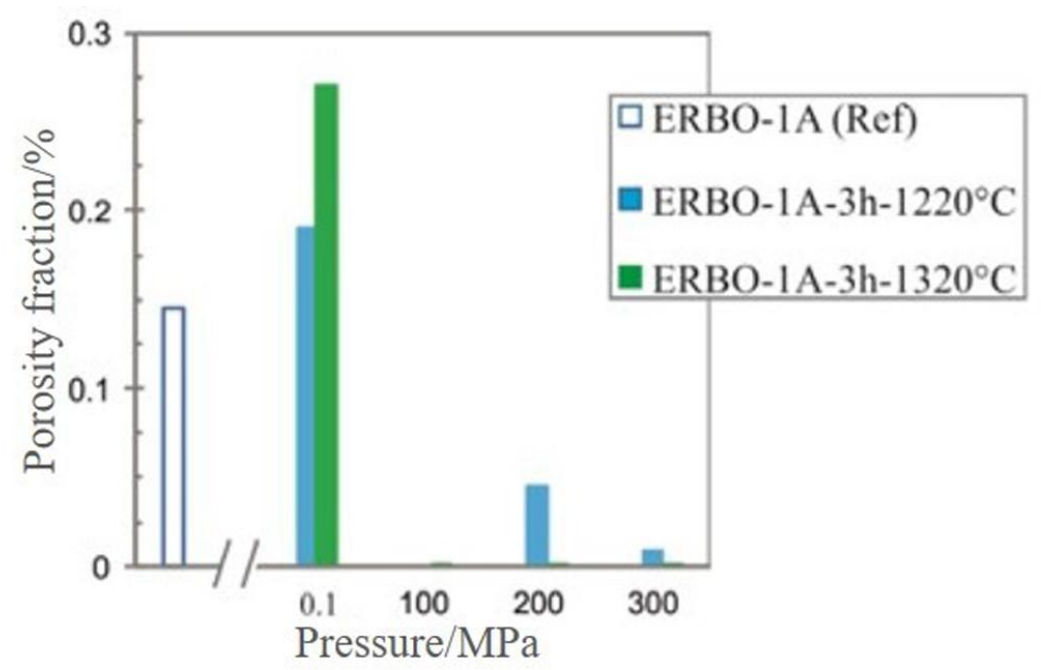

Fig.3. Porosity of as-cast ERBO-1A samples under different hot isostatic pressing schemes.

\subsection{Study on hole healing mechanism under hot isostatic pressure}

Generally speaking, under high temperature and high pressure, plastic deformation and creep behavior take place in the cavity area of the alloy, and then the surface of the collapse area is bonded under the action of diffusion behavior, so as to improve the densification of the material. Therefore, the internal microstructure of the alloy is optimized, the density is improved, and the composition uniformity is also improved under the action of hot isostatic pressing [16-17].

L. Mujica Roncery ${ }^{[18]}$ thinks that the main closing mechanism of holes is creep deformation. He has carried out a series of studies on the closing mechanism of holes under hot isostatic pressure. Under and above the dissolution temperature of $\gamma^{\prime}$ phase, the nickel base single crystal superalloy was treated by hot isostatic pressure respectively. Figure 4 shows the microstructure changes around the holes under the action of hot isostatic pressure. It is found that raft structure appears around the hole under stress when the temperature is lower than the dissolution temperature of $\gamma^{\prime}$ phase. When the temperature is higher than the dissolution temperature of the $\gamma$ 'phase, the dislocation is no longer fixed by the $\gamma$ ' phase due to the dissolution of the $\gamma$ 'phase in the hot isostatic pressing process, so the deformation of the hole is more rapid.

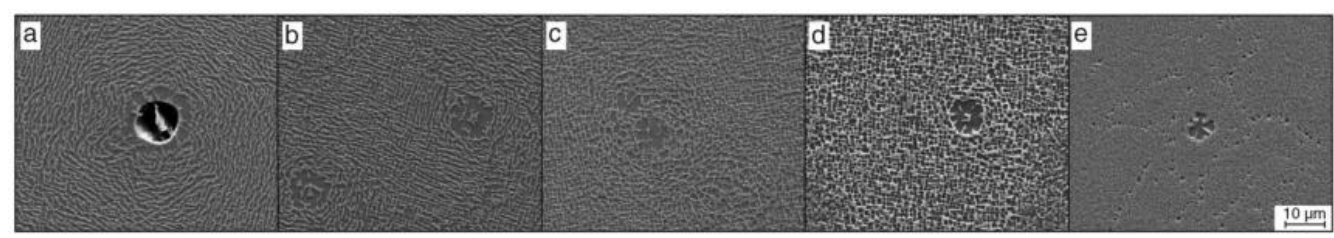

(a) (c) : lower than the dissolution temperature of $\gamma$ 'phase ; (d) (e) : higher than the dissolution temperature of $\gamma^{\prime}$ phase

Fig. 4. Microstructure of micropore area after hot isostatic pressing. 
Alexander Epishin ${ }^{[13]}$ studied the hole healing mechanism of nickel-based single crystal superalloy CMSX-4, and set up a series of interrupt experiments to explore the dynamic mechanism of hole healing. Analyzing the experimental results, the article considers that the hole closure is mainly caused by plastic deformation caused by dislocation slip. At the same time, the theory of crystal plasticity and large strain was used to model the dynamics of hole closure during the hot isostatic pressing process of single crystal superalloy. A physical model of the hole closing process was developed and studied the influence of different parameters of hot isostatic pressing on the dynamic process of hole closure. Figure 5 shows the comparison between the experimental and simulation results and the simulation results also verifies the mechanism of pore closure caused by plastic deformation.

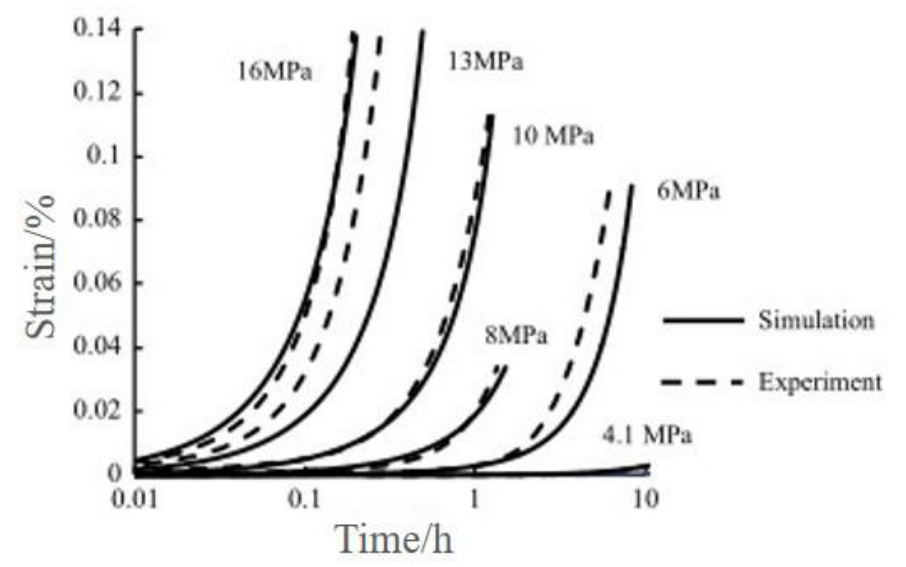

Fig.5. Comparison between experimental creep curve and simulated creep curve.

Zhou et al. ${ }^{[19-20]}$ studied the mechanism of hot isostatic pressure (HIP) on the repair of creep holes, and considered that temperature and pressure are two driving factors of solute diffusion, and their interaction affects the healing performance of creep holes. Based on the characteristics of hole repair and related thermodynamic theory, a hole repair model is proposed. In this model, the stress gradient around the hole is used as the driving force of atom diffusion to study the effect of hot isostatic pressure temperature and pressure on the healing dynamics of creep hole. The relations between the healing time and temperature and pressure was established (Fig. 6), thus providing a basis for the selection of HIP parameters. 


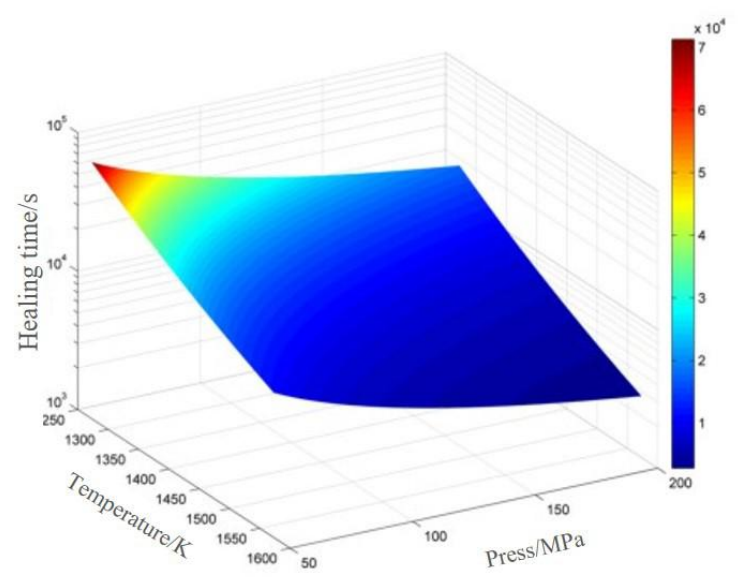

Fig. 6. Simulation of relationsHIP between time required for hole repair and HIP temperature and pressure.

\section{Effect of HIP on mechanical properties of nickel-based single crystal superalloy}

\subsection{Effect of hot isostatic pressing on tensile properties of nickel-based single crystal superalloy}

Lan ${ }^{[21]}$ et al. studied the change in tensile properties of single crystal superalloy under hot isostatic pressing. The hot isostatic pressing scheme shown in Figure 7 was used to perform hot isostatic pressing on the fully heat treated second-generation single crystal superalloy CMSX-4. Tensile tests were carried out at $980{ }^{\circ} \mathrm{C}$ on two groups of specimens treated with HIP or not, and the test results are shown in Figure 8. The study found that the average elongation at break of the samples without HIP treatment was $25.7 \%$, and the average elongation at break of the samples after HIP treatment increased significantly to $31.3 \%$, while the yield strength remained unchanged. By analyzing the fracture morphology, it can be concluded that HIP treatment can reduce the size and number of micropores in the alloy, thus inhibiting the crack initiation and propagation and improving the tensile properties of the alloy. 


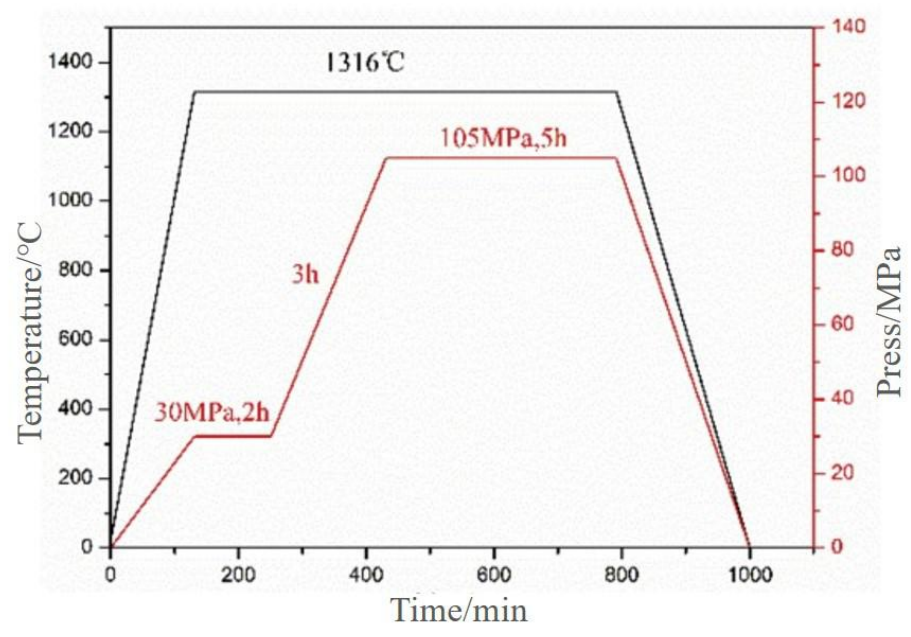

Fig.7. Hot isostatic pressing scheme.

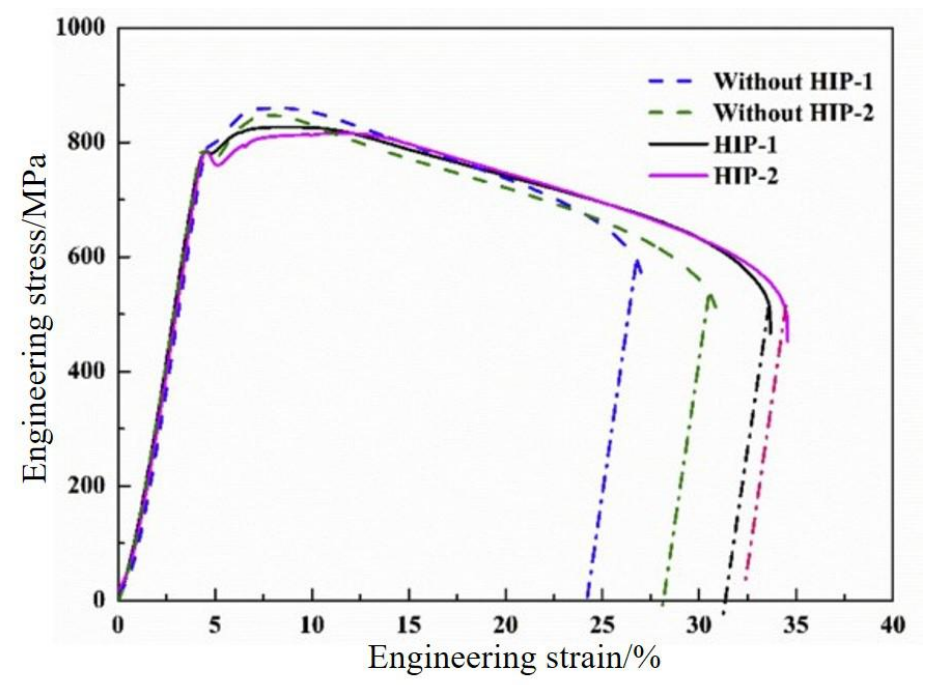

Fig.8. Engineering stress-strain curve of samples with and without HIP treatment at $980{ }^{\circ} \mathrm{C}$.

\subsection{Effect of hot isostatic pressing on the durability of nickel base single crystal superalloy}

Chang [22] treated the CMSX-4 alloy by hot isostatic pressing, and analyzed the microstructure and mechanical properties of the alloy. The research shows that the internal porosity of the alloy is not only significantly reduced after the hot isostatic pressing treatment, but also the endurance life increased from $72.7 \mathrm{~h}$ to $134.28 \mathrm{~h}$ at $950{ }^{\circ} \mathrm{C} / 355 \mathrm{MPa}$. The experimental results are shown in Figure 9. 


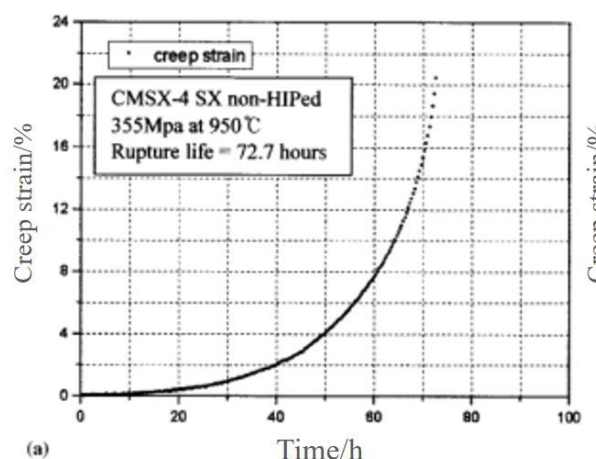

(a)

Time/h

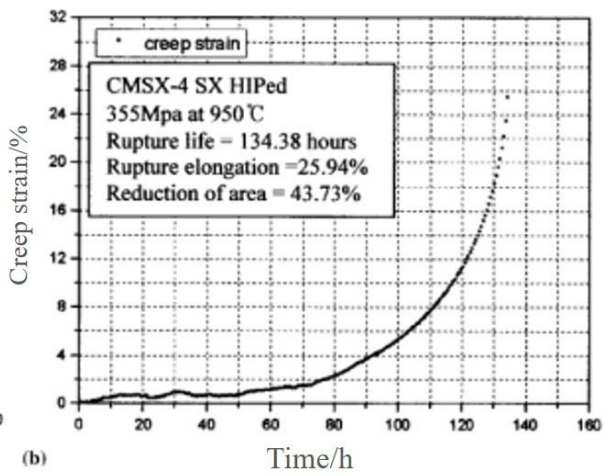

Time/h

Fig.9. Stress-strain curve of CMSX-4 alloy at $950^{\circ} \mathrm{C} / 355 \mathrm{MPa}$.

(a) No HIP treatment; (b) HIP treatment

Shi Zhenxue et al. ${ }^{[23]}$ subjected the as-cast nickel-based single crystal superalloy samples to hot isostatic pressing at $1180^{\circ} \mathrm{C} / 150 \mathrm{MPa}$. In order to compare the endurance properties of samples under different conditions, standard heat treatment is carried out for both the samples after HIP treatment and as cast samples, and the experimental results are shown in Table 3. It can be seen that the alloy's durable life is increased after hot isostatic pressing under the conditions of $760^{\circ} \mathrm{C} / 800 \mathrm{MPa}$ and $980^{\circ} \mathrm{C} / 250 \mathrm{MPa}$, while the alloy's durable life has not changed significantly under the condition of $1100^{\circ} \mathrm{C} / 140 \mathrm{MPa}$.

Table 3. Effect of hot isostatic pressing on the durability of alloy under different conditions

\begin{tabular}{|c|c|c|}
\hline test conditions & Treatment method & $\mathrm{t} / \mathrm{h}$ \\
\hline \multirow{2}{*}{$760^{\circ} \mathrm{C} / 800 \mathrm{MPa}$} & heat treatment & 353.5 \\
\cline { 2 - 3 } & HIP+heat treatment & 462.1 \\
\hline \multirow{2}{*}{$980^{\circ} \mathrm{C} / 250 \mathrm{MPa}$} & heat treatment & 225.2 \\
\cline { 2 - 3 } & HIP+heat treatment & 254.6 \\
\hline \multirow{2}{*}{$1100^{\circ} \mathrm{C} / 140 \mathrm{MPa}$} & heat treatment & 83.4 \\
\cline { 2 - 3 } & HIP+heat treatment & 85.1 \\
\hline
\end{tabular}

\section{Summary}

With the rapid development of nickel base single crystal superalloy and the sharp increase of domestic demand for nickel base single crystal superalloy products, people are eager to improve the temperature bearing capacity of the alloy and its comprehensive performance at high temperature, so as to develop advanced aircraft engines and gas turbines with higher thrust weight ratio and fuel efficiency. However, pores and other defects that cannot be avoided during the metal casting process restrict the development of the alloy to a certain extent, endanger the mechanical properties of the alloy and reduce the service life of the alloy. The hot isostatic pressing technology, as an effective method to eliminate the defects in the alloy, has been deeply studied by domestic and foreign scholars, and has been successfully applied in engineering. With the advent of hot isostatic pressing equipment with rapid cooling function, scholars have begun to study the combination of heat treatment process and hot isostatic pressing process to treat alloy products, so as to 
improve the overall performance of the alloy and greatly reduce the cost. At the same time, the research of HIP technology in the field of material repair, the combination of HIP and additive manufacturing and other advanced technologies was also carried out.

At present, the application research of China's hot isostatic pressing technology in the field of nickel-based single crystal superalloy still has a certain gap with foreign developed countries. The blockade of related foreign technologies and the lack of advanced hot isostatic pressing equipment restrict the engineering application of our country's hot isostatic pressing technology in the field of nickel-based single crystal superalloy. Most of the current scientific research work is limited to the characterization of microstructure and material properties while lacking in mechanism analysis and engineering application research. Therefore, the application of hot isostatic pressing technology in the field of nickel base single crystal superalloy still needs the active participation of more scientists. With the rapid development of aeroengine technology in China, the demand for turbine blades of nickel base single crystal superalloy is also increasing. It is believed that the application of hot isostatic pressing technology in the field of nickel base single crystal superalloy will be developed rapidly in the near future.

\section{References}

1. Z. Q. Hu, L. R. Liu, T. Jin, \& X. F. Sun, Aeroengine, 31 (3), 1-7 (2005).

2. R. Z. Chen, Journal of Materials Engineering, (8): 3-12 (1995).

3. R. C. Reed, The Superalloy: Fundamental and Applications, 1 (2006).

4. J. R. Li, J. C. Xiong, D Z. Tang, et al. National Defense Industry Press, 175 (2012).

5. T. Link, S. Zabler, A. Epishin, A. Haibei, M. Bansal, MSEA, 425: 47-54 (2006).

6. B.S. Bokstein, A. Epishin, T. Link, V.A. Esin, A.O. Rodin, I.L. Svetlov, Scripta Materialia, 57: 801-804 (2007).

7. A. Epishin, T. Link, U. Brückner, P. D. Portella, Materialsfor advanced power engineering, 217-226 (2002).

8. J. Zhang, L. H. Lou, AcatMetallurgicaSinica, 54 (11): 1637-1652 (2008).

9. H. Hu, AcatMetallurgicaSinica, 38 (11): 1699-1202 (2002).

10. A. Weddeling, W. Theisen, Metal Powder Report, 72 (5): 345-348 (2017).

11. M. Han, Y. S. Luo, Journal of Materials Engineering, (8): 40-43 (2008).

12. R. Bürgel, P. D. Portella, J. Preuhs, Superalloy. Champion, USA: TMS, 229-238 (2000).

13. A. Epishin, B. Fedelich, T. Link, et al. Materials Science \& Engineering A, 586: 342349 (2013).

14. L. M. Cao, L. J. Liu, J. Y. Chen, et al. Journal of Materials Engineering, (6): 1-4 (2013).

15. A. Epishin, T. Link , B. Fedelich, et al. MATEC Web of Conferences. Vol. 14. EDP Sciences, 2014.

16. J. C. Chang, C. Choi, J. C. Kim, et al. Journal of Materials Engineering and Performance, 12 (4): 420-425 (2003).

17. R. F. Huang, W. H. Yu, Y. J. Tang, et al. Materials of Mechanical Engineering, (3): 50-53 (1988).

18. M. L. Roncery, I. Lopez-Galilea, B. Ruttert, et al. Materials and Design, 97: 544-552 (2016). 
19. Y. Zhou, S. X. Rao, Z. Zhang, et al. Materials and Design, 49: 25-27 (2013).

20. Y. Zhou, Z. Zhang, Q. P. Zhong. et al. Computational Materials Science, 65: 320-323 (2012).

21. J. Lan, W. D. Xuan, Y. Han, et al. Journal of Alloys and Compounds, 805: 78-83 (2019).

22. J. C. Chang, C. Choi, J. C. Kim, et al. Journal of materials engineering and performance, 12 (4), 420-425 (2003).

23. Z. X. Shi, S. Z. Liu, J. C. Xiong, Rare Metal Materialsand Engineering, 44 (9): 23002304 (2015). 